\title{
SPECIAL REPORT \\ Revised diagnosis and severity criteria for sinusoidal obstruction syndrome/veno-occlusive disease in adult patients: a new classification from the European Society for Blood and Marrow Transplantation
}

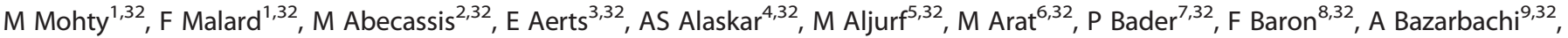 \\ D Blaise ${ }^{10,32}$, F Ciceri ${ }^{11,32}$, S Corbacioglu ${ }^{12,32}$, J-H Dalle $^{13,32}$, F Dignan $^{14,32}$, T Fukuda $^{15,32}$, A Huynh ${ }^{16,32}$, T Masszi $^{17,32}$, M Michallet $^{18,32}$, \\ A Nagler ${ }^{19,32}$, M NiChonghaile ${ }^{20,32}$, S Okamoto ${ }^{21,32}$, A Pagliuca ${ }^{22,32}$, C Peters ${ }^{23,32}$, FB Petersen ${ }^{24,32}$, PG Richardson $^{25,32}$, T Ruutu ${ }^{26,32}$, \\ BN Savani ${ }^{27,32}$, E Wallhult ${ }^{28,32}$, I Yakoub-Agha ${ }^{29,32}$, RF Duarte ${ }^{30,32}$ and E Carreras ${ }^{31,32}$
}

Sinusoidal obstruction syndrome, also known as veno-occlusive disease (SOS/VOD), is a potentially life threatening complication that can develop after hematopoietic cell transplantation. Although SOS/VOD progressively resolves within a few weeks in most patients, the most severe forms result in multi-organ dysfunction and are associated with a high mortality rate ( $>80 \%)$. Therefore, careful attention must be paid to allow an early detection of SOS/VOD, particularly as drugs have now proven to be effective and licensed for its treatment. Unfortunately, current criteria lack sensitivity and specificity, making early identification and severity assessment of SOS/VOD difficult. The aim of this work is to propose a new definition for diagnosis, and a severity-grading system for SOS/VOD in adult patients, on behalf of the European Society for Blood and Marrow Transplantation.

Bone Marrow Transplantation (2016) 51, 906-912; doi:10.1038/bmt.2016.130; published online 16 May 2016

\section{INTRODUCTION}

Sinusoidal obstruction syndrome (SOS), also known as veno-occlusive disease (VOD; referred to as SOS/VOD hereafter) remains a potentially devastating complication after hematopoietic cell transplantation (HCT). ${ }^{1}$ Toxic metabolites generated by the conditioning regimen damage the sinusoidal endothelial cells and hepatocytes in zone 3 of the hepatic acinus. ${ }^{2}$ Therefore, activated sinusoidal endothelial cells round up, favoring the appearance of gaps in the sinusoidal barrier. RBC, leukocytes and cellular debris pass through these gaps into the space of Disse beneath the endothelial cells, and dissect the endothelial lining. The venous lumen progressively narrows and sinusoidal venous outflow is reduced, resulting in post-sinusoidal portal hypertension. ${ }^{1}$ This pathophysiological process leads to the clinical syndrome of SOS NOD, consisting of weight gain, fluid retention with ascites, painful hepatomegaly, jaundice and, in severe cases, multi-organ dysfunction (also known as multi-organ failure, thereafter referred as MOD/MOF), characterized by pulmonary and renal dysfunction, as well as encephalopathy. ${ }^{1,3-5}$ SOS/VOD usually develops within 3 weeks after HCT, although in $15-20 \%$ it can occur later. ${ }^{6,7}$

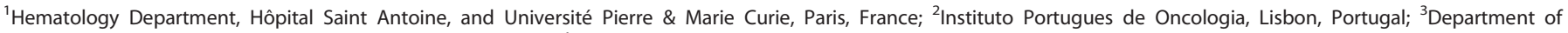

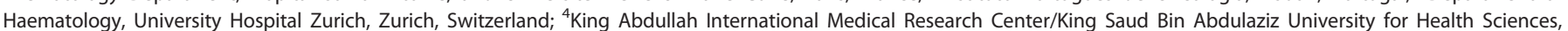

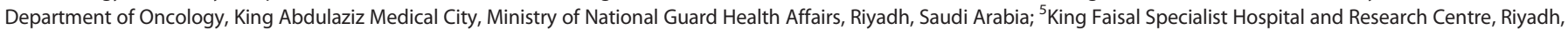

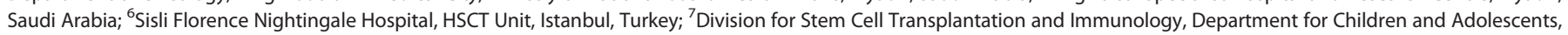

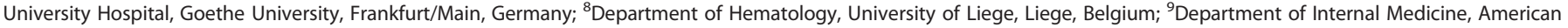

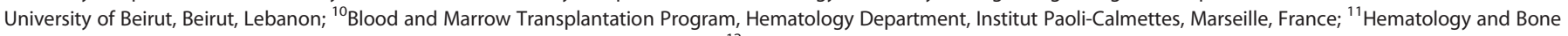

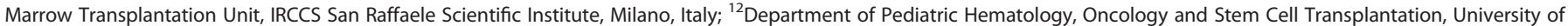

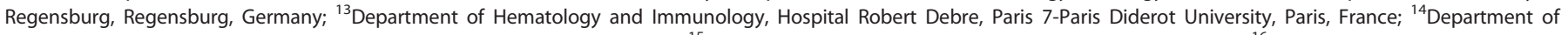

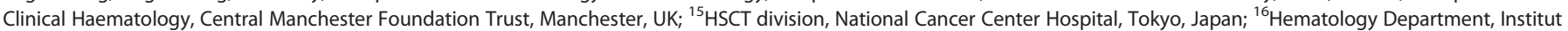

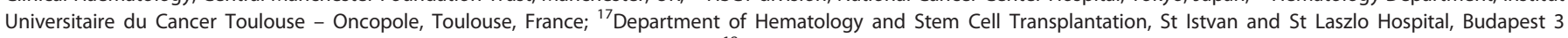

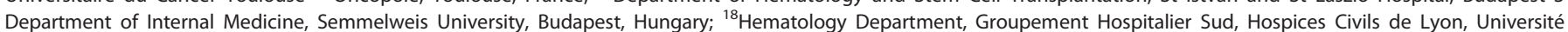

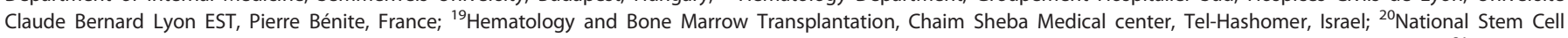

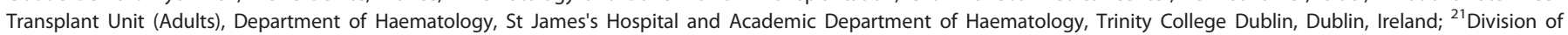

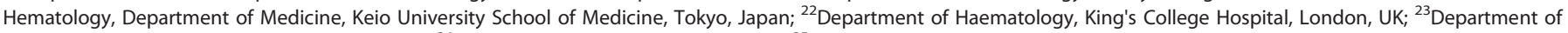

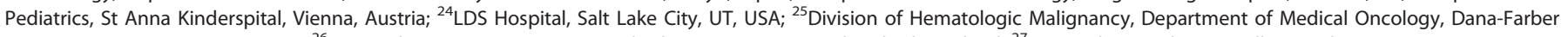

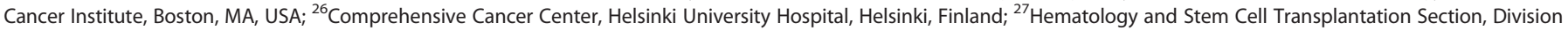

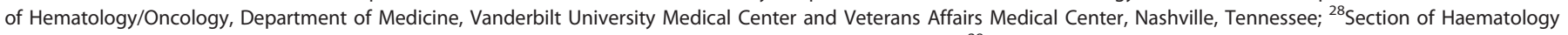

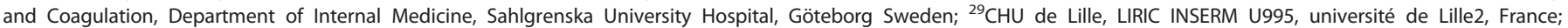

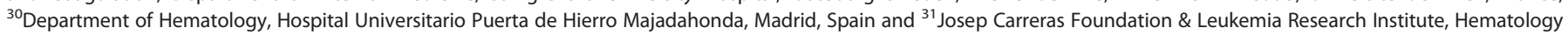

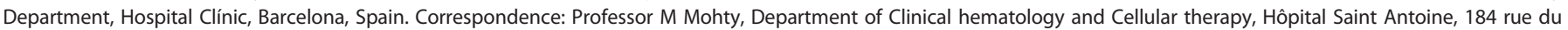
Faubourg Saint Antoine, Paris 75571 Cedex 12, France.

E-mail: mohamad.mohty@inserm.fr

${ }^{32}$ These authors contributed equally to this work.

Received 17 March 2016; revised 30 March 2016; accepted 1 April 2016; published online 16 May 2016 
The incidence of SOS/VOD varies with the intensity of the conditioning regimen, the type of transplant and the presence of risk factors, but also with the clinical criteria used for SOS/VOD diagnosis. At present, the incidence is $~ 10-15 \%$ after allogeneic $\mathrm{HCT}$ (allo-HCT) conditioned with a myeloablative conditioning (MAC) regimen, against $<5 \%$ after autologous HCT and allo-HCT conditioned with reduced intensity/toxicity conditioning regimen. ${ }^{1,5,8-10}$ Although the SOS/VOD progressively resolves within a few weeks in most patients, the most severe forms result in MOD/MOF, and are associated with a high mortality rate $(>80 \%) .^{5,11}$ For this reason, despite the relatively low incidence of this complication, early detection of SOS/VOD should be a priority, particularly now that a new drug, defibrotide, has proven to be effective for its prevention and treatment. ${ }^{11-15}$ Unfortunately, current criteria lack sensitivity and specificity, making early identification of SOS/VOD difficult. The aim of this work is to propose a new definition for SOS/VOD diagnosis and severity in adult patients, on behalf of the European Society for Blood and Marrow Transplantation (EBMT).

\section{RATIONALE FOR THE NEW DIAGNOSTIC CRITERIA}

Currently, two conflicting definitions of SOS/VOD coexist, based on the Seattle criteria, reported by McDonald in $1984^{3}$ and the Baltimore criteria, reported by Jones in $1987 .{ }^{4}$ With minor clarifications/modifications, ${ }^{15-17}$ these criteria have been used in clinical practice, as well as in research studies and trials, in the past three decades. ${ }^{11,15}$ According to a recent meta-analysis, the SOS/VOD incidence varied according to the criteria used between $17.3 \%$ (Seattle) and $9.6 \%$ (Baltimore). ${ }^{5}$ One of the major difficulties is that, unlike some other transplant-related complications, SOS/VOD is very dynamic in its manifestations, and the exact definition is hard to establish; the diagnosis of severe forms needs overt clinical manifestations, MOD/MOF and serious organ

Table 1. Risk factors for SOS/VOD

Transplant-related factors

Unrelated donor

HLA-mismatched donor

Non T-cell-depleted transplant

Myeloablative-conditioning regimen

Oral or high-dose busulfan-based regimen

High-dose TBI-based regimen

Second $\mathrm{HCT}$

Patient and disease-related factors

Older age

Karnofsky score below $90 \%$

Metabolic syndrome

Female receiving norethisterone

Advanced disease (beyond second CR or relapse/refractory)

Thalassemia

Genetic factors (GSTM1 polymorphism, C282Y allele, MTHFR

677CC/1298CC haplotype)

Hepatic-related

Transaminases $>2.5$ ULN

Serum bilirubin $>1.5$ ULN

Cirrhosis

Active viral hepatitis

Abdominal or hepatic irradiation

Previous use of gemtuzumab ozogamicin or inotuzumab ozogamicin

Hepatotoxic drugs

Iron overload

Abbreviations: $\mathrm{SOS}=$ sinusoidal obstruction syndrome; ULN = upper limit of normal; $\mathrm{VOD}=$ veno-occlusive disease. damage, such as severe pulmonary or renal dysfunction and encephalopathy, before the diagnosis can be made.

This conundrum has resulted in patients not getting early therapy to prevent MOD/MOF, and has prevented attempts to treat at a stage when the disease is in a more favorable response state. The current criteria were acceptable in an era when the available treatment was restricted and carried substantial toxic effects, and early intervention did not elicit any apparent clinical benefit. $^{18-21}$ However, they can no longer be justified, because treatment options are available, and data show that early intervention is justifiable and effective. ${ }^{11}$ Moreover, the development of alternative donors and reduced intensity/toxicity regimens $^{22}$ led to a change in the natural history of HCT, and increased frequency of late onset SOS/VOD, an observation that should be taken into account for revised diagnostic criteria. Likewise, new risk factors, related to these changes of HCT practice, have been identified and should be taken into account for prognosis assessment. Similarly, advances in imaging techniques may call for an update on the specific variables that should be used for diagnosis and prognosis assessment. ${ }^{23}$ Finally, while current SOS/VOD definitions apply to both adults and children, the clinical presentation of this complication differs between these two patient populations. Thus, while most of adult patients have hyperbilirubinemia, ${ }^{24}$ the incidence of SOS/VOD (including its severe form) without hyperbilirubinemia in children is $~ 30 \% .{ }^{15}$ Therefore, a proposal for distinct diagnostic criteria for adults and children seems to be mandatory. This paper focuses on adult patients; diagnostic criteria for children will be developed in another article.

\section{SOS/VOD RISK FACTORS}

To intervene before the development of end-organ damage and MOD/MOF in SOS/VOD, there is a need for accurate identification of risk factors and biomarkers to identify the subset of patients with a likely severe form of the disease and at imminent risk of deteriorating. There are three different kinds of SOS/VOD risk factors: those directly related to the transplant; those related to the patient's characteristics and underlying disease; and hepatic-related risk factors (Table 1).

\section{Transplant-related risk factors}

These are directly related to the choice of the intensity of the conditioning regimen, the type of donor and HLA-matching or the GvHD prophylaxis. Given alloreactivity contributes to endothelial damage and SOS/VOD pathophysiology, the risk of SOS/VOD increases with the alloreactivity level. It is higher after allo-HCT as compared with autologous HCT. ${ }^{5,8}$ However, allo-HCT by itself can no longer be considered as a risk factor. Rather, only situations where the alloreactivity of the transplant is increased, such as with the use of an unrelated or an HLA-mismatched donor, and a non T-cell-depleted graft should be considered as risk factors. ${ }^{25,26}$ Of note HLA-haploidentical familial donors are increasingly used ${ }^{27}$ and while no study specifically address the risk of SOS/VOD in this setting, we suggest that the use of a haploidentical donor could be considered as a risk factor as any HLA-mismatched donor.

The risk of SOS/VOD onset also depends on the conditioning regimen intensity and the drugs used. It is higher after high-dose busulfan or TBI-based conventional MAC, compared with RIC. ${ }^{5,10,28,29}$ Similarly, unfractionated or high-dose TBI $\left(\geqslant 12\right.$ Gray), ${ }^{8}$ and/or a combination of busulfan and cyclophosphamide lead to an increased incidence of SOS/VOD. ${ }^{8}$ Oral busulfan may be replaced by i.v. busulfan, which is easier to monitor, has a predictable pharmacokinetic profile, and is associated with a lower risk of SOS/VOD. ${ }^{30,31}$

Some drugs for GvHD prophylaxis have been reported to increase the incidence of SOS/VOD. For instance, compared 
with the combination of tacrolimus+sirolimus and tacrolimus +methotrexate the combination of tacrolimus+sirolimus+ methotrexate after MAC TBI-based allo-HCT is associated with an increased risk of SOS/NOD, ${ }^{32}$ leading the authors to conclude that use of sirolimus is associated with SOS/VOD. Nevertheless, preclinical data have shown that while sirolimus alone has no effect, cyclosporine alone, tacrolimus alone and the combination of tacrolimus+sirolimus, have a proinflammatory and prothrombotic effect on endothelial cells, ${ }^{33}$ suggesting it was the association of sirolimus with another immunosuppressive therapy and not sirolimus alone that contributed to endothelial cell damage and, consequently, to SOS/VOD onset. ${ }^{33}$ Overall, the effect of GvHD prophylaxis on endothelial cells probably depends on concomitant treatments. At present, the available data are too preliminary to conclusively identify a specific form of GvHD prophylaxis as a SOS/VOD risk factor. Finally, second allo-HCT should also be considered as a risk factor for SOS/VOD. ${ }^{10}$

\section{Patient and disease-related factors}

Reported patient-related risk factors for SOS/VOD are older age, impaired Karnofsky status $(<90)$ and metabolic syndrome. ${ }^{1,8,10}$ In addition, an increased incidence of SOS/VOD has been reported in women, but it was related to the use of norethisterone to prevent gynecological bleeding. ${ }^{34}$ Genetic factors, such as GSTM1-null genotype, ${ }^{35}$ the presence of the hemochromatosis C282Y allele, ${ }^{36}$ and the MTHFR 677CC/1298CC haplotype in patients receiving MAC regimen with oral busulfan ${ }^{37}$ are associated with an increased risk of SOS/VOD. This is also observed in patients with advanced diseases (beyond CR2 or relapse) and in those with thalassemia. ${ }^{1,8,10}$ Risk factors specific to the pediatric setting are not discussed here (primarily hemophagocytic lymphohistiocytosis, osteopetrosis or thalassemia major, auto-HCT in patients with neuroblastoma, younger age (under 1-2 years of age) and low weight). ${ }^{1}$

Hepatic-related factors

Hepatic dysfunction before transplant, with increased levels of bilirubin and transaminase, is one of the main risk factors of SOS/VOD. 8,17,38 This level of dysfunction can be found in preexisting liver disease, such as cirrhosis, fibrosis and active viral hepatitis, or as a result of previous abdominal or hepatic irradiation, or the use of hepatotoxic drugs such as gemtuzumab ozogamicin or inotuzumab ozogamicin. ${ }^{8,17,39,40}$ Finally, elevated ferritin level and iron overload are also considered as SOS/VOD risk factors. ${ }^{41,42}$

\section{BIOMARKERS AND IMAGING CRITERIA}

\section{Biomarker}

The roles of endothelial cell injury and of microthrombus formation in SOS/VOD pathophysiology have prompted investigations on their potential as biomarkers of the disease. Two studies reported an elevated level of plasminogen activator inhibitor (PAI-1) at diagnosis of SOS/VOD, ${ }^{43,44}$ and one group showed that, besides its diagnostic value, PAI-1 levels may also be a prognostic factor. ${ }^{45}$ Similarly, a decrease in protein $C$, alone ${ }^{46}$ or in combination with a decrease of antithrombin $\mathrm{III}^{47}$ or of factor $\mathrm{VII}^{48}$ or an increase of tissue plasminogen activator and $\mathrm{N}$-terminal propeptide for type III procollagen ${ }^{49}$ before the onset of SOS/VOD have been reported. As to the von Willebrand factor, it was found to be increased in one study, ${ }^{48}$ but this was not confirmed in another. ${ }^{50}$ Cutler et al. ${ }^{51}$ reported that increased levels of von Willebrand factor, thrombomodulin and soluble intercellular adhesion molecule-I were predictive of SOS/VOD, but, this result was limited to patients receiving sirolimus as GvHD prophylaxis. Akil et al. ${ }^{52}$ used quantitative mass spectrometry- based proteomic approach to identify candidate biomarkers by comparing plasma pooled from 20 patients with and 20 without SOS/VOD. Six candidate proteins identified by this approach and five others selected from the literature were evaluated in samples from 80 patients. Suppressor of tumorigenecity-2, angiopoietin-2, L-ficolin, hyaluronic acid and vascular cell adhesion molecule-1 (VCAM1) were found to be biomarkers for diagnosis of SOS/VOD. Furthermore, L-ficolin, hyaluronic acid and VCAM1 also stratified patients at risk of SOS/VOD at day 0 of allo-HCT. Of note in that study, the diagnostic role of PAl-1 and von Willebrand factor was not confirmed. ${ }^{52}$ Overall, the combined investigations produced conflicting results, and none of these biomarkers is currently routinely used. Given the complexity of allo-HCT techniques, the hope to identify a biomarker valid in all settings is unlikely to be successful. ${ }^{1}$ Therefore, further validation of these biomarkers in the setting of a clinical trial is indispensable, after which, they may be included in the criteria for diagnosis of SOS/VOD.

\section{Imaging techniques}

Imaging techniques have experienced major progress since the 1980 s and the initial definition of the criteria for diagnosis of SOS/VOD, ${ }^{3,4}$ raising the possibility that they may contribute to refining such diagnosis today. The role of ultrasound has been investigated in several studies, but most of them were published almost two decades ago, with conflicting results, as reviewed by Mahgerefteh et al. ${ }^{53}$ The reported abnormalities in SOS/VOD are not specific, and included hepatomegaly, splenomegaly, gallbladder wall thickening, ascites and portal venous flow abnormalities. ${ }^{53,54}$ The latter-decrease in velocity or reversal of the portal venous flow-are considered more specific for SOS/VOD, but usually occur late in the disease, ${ }^{53-55}$ and their interest for SOS/VOD early diagnosis is limited.

Measurement of the hepatic venous gradient pressure through the jugular vein is the most accurate method to confirm the diagnosis of SOS/VOD. ${ }^{24,56,57}$ However, this technique is invasive, requires an expert hemodynamist, and is not routinely available in most centers. Therefore, doppler ultrasonography has been investigated to evaluate changes in portal circulation. Although the correlation between hepatic arterial resistive indices and portal hypertension is controversial, the hepatic arterial early acceleration index correlated directly with Hepatic venous pressure gradient. ${ }^{58}$ Nevertheless, although non-invasive, this technique requires expert echographers, and is not available in most centers.

Few studies, mostly case reports, investigate the role of other imaging techniques. ${ }^{23}$ Periportal edema, ascites and a narrow right hepatic vein on computerized tomography scans are suggestive of SOS/VOD. ${ }^{59,60}$ Similarly, magnetic resonance imaging scans of patients with SOS/VOD have detected hepatomegaly, ascites, hepatic vein narrowing, gallbladder wall thickening, peri-portal cuffing or patchy signal enhancement of the liver. ${ }^{59,61-64}$ Of note, a high specificity of supramagnetic iron oxide-enhanced magnetic resonance imaging and gadoteric acid-enhanced magnetic resonance imaging for SOS/VOD diagnosis in patients with chemotherapy-treated colorectal liver metastases has been reported, ${ }^{65,66}$ but these imaging modalities have not been evaluated in the setting of HCT.

At present, the role of imaging in SOS/VOD remains limited to ultrasound to assist in the exclusion of differential diagnoses. In addition, ultrasound may be helpful to confirm clinical findings such as hepatomegaly and ascites, which can be difficult to assess in particular in overweight patients. Baseline and serial ultrasound measurements may be useful for early detection of signs suggestive of SOS/VOD, although daily clinical examination and weight monitoring remain the gold standards. Prospective evaluation of hepatic arterial early acceleration index and of supramagnetic iron oxide- or gadoteric acid-enhanced magnetic 
resonance imaging for SOS/VOD monitoring/diagnosis seems indispensable before recommending their use and integration into the SOS/VOD diagnostic criteria.

\section{NEW EBMT CRITERIA FOR DIAGNOSIS OF SOS/VOD}

The updated EBMT criteria for diagnosis of SOS/VOD in adult patients are given in Table 2. The supporting data for each of the changes are discussed below.

Symptoms of SOS/VOD are typically observed within the first weeks after HCT, and both modified Seattle ${ }^{17}$ and Baltimore ${ }^{4}$ criteria require that patients must be within 21 days after HCT to make the diagnosis of this complication. However, late onset SOS/VOD beyond day 21 has been reported. ${ }^{7}$ The investigators thus recommend including late onset SOS/VOD (beyond day 21) in these clinical criteria.

Carreras et al. ${ }^{24,67}$ reported that haemodynamic studies could not confirm the diagnosis of SOS/VOD diagnosis in $42 \%$ of adult patients with only two clinical manifestations listed in the Seattle

\begin{tabular}{|c|c|}
\hline $\begin{array}{l}\text { Classical SOS } / V O D \\
\text { In the first } 21 \text { days after HSCT }\end{array}$ & $\begin{array}{l}\text { Late onset SOS/VOD } \\
>21 \text { Days after HSCT }\end{array}$ \\
\hline \multirow{2}{*}{$\begin{array}{l}\text { Bilirubin } \geqslant 2 \mathrm{mg} / \mathrm{dL} \text { and two } \\
\text { of the following criteria must } \\
\text { be present: }\end{array}$} & Classical VOD/SOS beyond day 21 \\
\hline & OR \\
\hline Painful hepatomegaly & Histologically proven SOS/VOD \\
\hline Weight gain $>5 \%$ & OR \\
\hline Ascites & $\begin{array}{l}\text { Two or more of the following criteria } \\
\text { must be present: } \\
\text { Bilirubin } \geqslant 2 \mathrm{mg} / \mathrm{dL} \text { (or } 34 \mu \mathrm{mol} / \mathrm{L} \text { ) } \\
\text { Painful hepatomegaly } \\
\text { Weight gain }>5 \% \\
\text { Ascites } \\
\text { AND Hemodynamical or/and } \\
\text { ultrasound evidence of SOS/VOD }\end{array}$ \\
\hline $\begin{array}{l}\text { Abbreviations: EBMT = Europear } \\
\text { tation; SOS = sinusoidal obstr } \\
\text { disease. These symptoms } / \text { signs }\end{array}$ & $\begin{array}{l}\text { Society for Blood and Marrow Transplan- } \\
\text { action syndrome; VOD = veno-occlusive } \\
\text { hould not be attributable to other causes. }\end{array}$ \\
\hline
\end{tabular}

criteria, compared with only $9 \%$ using the Baltimore criteria. The main difference between the two classifications is hyperbilirubinemia, mandatory in the Baltimore, but not in the modified Seattle criteria. Hyperbilirubinemia and jaundice are rarely absent in adults with classical SOS/VOD, but can be absent in SOS/VOD that develops later. ${ }^{24}$ Therefore, most groups treating adult patients prefer to use the Baltimore criteria, including in the setting of prospective clinical trials. ${ }^{11}$ Therefore, for classical SOS/VOD, which occurs within the first 21 days after HCT, and despite the fact that hyperbilirubinemia can be a delayed manifestation in SOS/VOD (occurring lately after liver pain and fluid retention), the group decided to keep using the Baltimore criteria.

Beyond day 21, the Baltimore criteria are still valid to establish the diagnosis of SOS/VOD. However, this may represent a problem in patients who develop late onset SOS/VOD in the absence of hyperbilirubinemia, with only weight gain and ascites. ${ }^{6,7,24}$ Therefore, hyperbilirubinemia should no longer be mandatory in late onset SOS/VOD, and the diagnosis of late onset SOS/VOD may be made if patients fulfill a less stringent version of the Baltimore criteria, that is, at least two of the following: bilirubin $\geqslant 2 \mathrm{mg} / \mathrm{dL}$, painful hepatomegaly, weight gain $>5 \%$ or ascites. However, hemodynamic and/or ultrasound evidence of SOS/VOD (hepatomegaly, ascites and decrease in velocity or reversal of the portal flow) is mandatory in addition to these criteria. Finally, although transjugular liver biopsy is invasive and difficult to perform, histological evidence of SOS/VOD remains the gold standard (but not mandatory) for the diagnosis. ${ }^{56,57}$

Obviously, many other causes can also lead to liver dysfunction after HCT, such as hepatic GvHD, viral infection, iron overload, sepsis and drug toxicity. Patient history, concomitant symptoms and laboratory testing allow exclusion of these differential diagnoses. However, one must keep in mind that SOS/VOD may coexist with others conditions presenting common symptoms.

Peripheral thrombocytopenia with a rapid consumption of transfused platelets is frequently observed in patients with SOS/VOD, ${ }^{24,68}$ and it has been debated whether it should be included as a diagnostic criterion. However, this feature is difficult to evaluate during the pancytopenic phase after conditioning, ${ }^{24}$ and lack specificity, given the numerous causes of thrombocytopenia after HCT. Therefore thrombocytopenia with rapid platelet consumption was not retained as a criterion for SOS/VOD diagnosis.

Table 3. New EBMT criteria for severity grading of a suspected SOS/VOD in adults

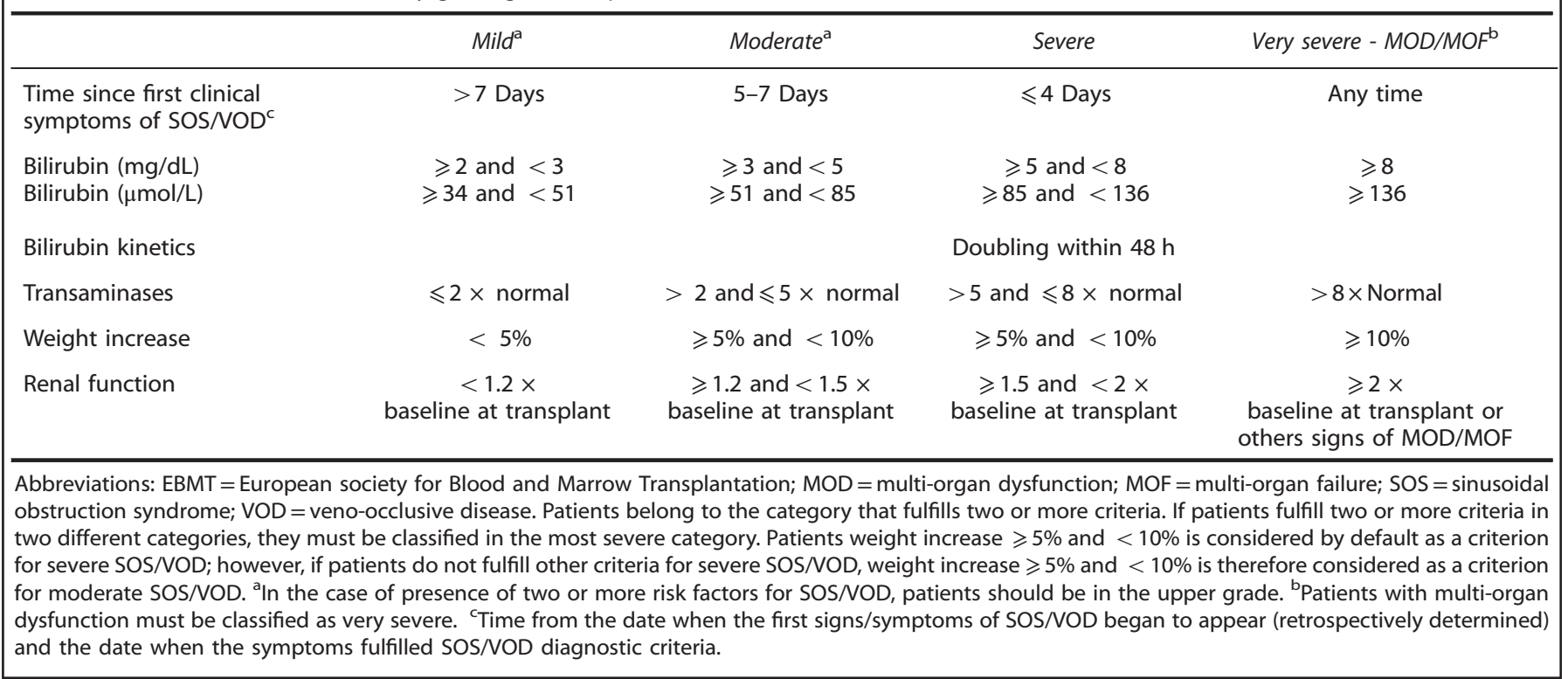




\section{NEW EBMT CRITERIA FOR SEVERITY GRADING OF SUSPECTED SOS/VOD IN ADULTS}

Currently, once the diagnosis of SOS/VOD is established, we lack a score to truly assess its severity, and to identify patients requiring early therapeutic intervention. This is particularly relevant, since treatment options are available, and data show that early intervention is justifiable. ${ }^{69}$ Bearman et al. ${ }^{70}$ attempted to develop a logistic regression model to estimate probabilities of severe SOS/VOD at different time points after MAC allo-HCT. In that model, early serum bilirubin and weight gain can estimate $50 \%$ or higher probability of developing severe SOS/VOD. However, the model was helpful in only a minority of patients who developed severe SOS/VOD within the first 16 days after a MAC allo-HCT. ${ }^{70}$ More recently, the concept of SOS/VOD grade based on measurable clinical data has been introduced. ${ }^{24,71}$

We propose new EBMT criteria for grading SOS/VOD severity in adult patients and to guide therapy decisions, based on the level of bilirubin and its rate of change, liver function (transaminase), weight increase, renal function and the kinetic of their onset (Table 3). This grading system is divided into five categories, as in the Common Terminology Criteria for Adverse Events: grade 1 =mild; grade 2 =moderate; grade 3 =severe; grade $4=$ very severe; and grade $5=$ death.

It is well established that serum bilirubin levels increase with the severity of SOS/VOD. ${ }^{17,24,70,72}$ Therefore, serum bilirubin level cutoff points have been defined to reflect this correlation. In addition, particular emphasis is placed on the rate of increase of serum bilirubin. Indeed, the risk of developing a severe SOS/VOD in a patient whose serum bilirubin level increases from 3 to $6 \mathrm{mg} / \mathrm{dL}$ within $48 \mathrm{~h}$ is higher than that of a patient who reaches this level over a longer period. ${ }^{17,72}$ Therefore, we decided to take into account the bilirubin kinetics in our grading system. A serum level doubling within $48 \mathrm{~h}$ is a criterion for classification of SOS/VOD as severe (for example, a bilirubin increase from 3 to $6 \mathrm{mg} / \mathrm{dL}$ within $48 \mathrm{~h}$ is sufficient to classify the SOS/VOD as severe). However, attention must be paid to other possible causes of rapid increase of serum bilirubin level, before retaining this criterion. Of note, bilirubin level and kinetics are not exclusive.

Like serum bilirubin, liver dysfunction increases with the severity of SOS/VOD. ${ }^{24}$ As the levels of transaminases appear to be the most relevant parameter to evaluate liver dysfunction, cutoff points have also been defined to reflect this correlation.

Weight increase is part of the diagnostic criteria of SOS/VOD and also reflects the development of ascites. Weight gain is directly correlated with the severity of the pathophysiological process at play in SOS/VOD. ${ }^{1,38,70}$ Therefore, it appears to be a relevant parameter for evaluation of SOS/VOD severity. A weight gain of more than 5 or $10 \%$ will be a criterion to classify SOS/VOD as moderate/severe or very severe, respectively. Given the difficulty in practice to objectively assess a little variation in weight, we decided not to define a weight gain threshold for distinguishing mild SOS/VOD. Of note, weight increase must be assessed when patients have received an optimal diuretic treatment.

Post-sinusoidal portal hypertension and volume loss in the third space (edema, ascites) leads to hypovolemia and to renal failure. The association between severity of SOS/VOD and renal failure has been reported in numerous studies. ${ }^{17,73-76}$ In order to grade the latter, creatinemia cutoff points have been defined in our criteria set.

The kinetics of appearance of the symptoms are also of major importance to evaluate the severity of SOS/VOD. A patient whose symptoms emerge within days, is much more likely to develop a severe SOS/VOD, than one whose symptoms emerge over a period $>7$ days. ${ }^{24,38,70}$ Therefore, a criterion evaluating the time from the date when the first signs of SOS/VOD began to appear (retrospectively determined) and the date when the diagnosis of
SOS/VOD is effectively performed has been introduced in our grading system.

Patients belong to the category that fulfills two or more criteria (bilirubin level, bilirubin kinetics, liver function, weight increase, renal function and symptom kinetics). If a patient fulfills two or more criteria in two different categories, he/she must be classified in the most severe category. In addition, patients with MOD/MOF will be systematically classified as very severe. ${ }^{5,11-13,24}$ This is defined as a clinical syndrome characterized by the development of progressive and potentially reversible physiologic dysfunction in two or more organs. ${ }^{77}$ Within the proposed new EBMT criteria, renal failure is defined as creatinemia $\geqslant 2$ times the baseline at transplant, or creatinine clearance $\leqslant 50 \%$ level at transplant, or dialysis; pulmonary failure as oxygen saturation $\leqslant 90 \%$ on room air and/or the need for positive pressure/ventilator dependence not attributable to any other cause; central nervous system failure as confusion, lethargy and/or delirium not attributable to any other cause. $^{24}$

In addition, particular attention should be paid to the number of SOS/VOD risk factors. The risk of developing a severe form of the disease may increase with the number of risk factors. Therefore, we suggest that, in the presence of two or more risk factors, mild SOS/VOD should be classified as moderate and moderate SOS/ VOD as severe. This is particularly important since it may allow earlier treatment in patients with multiple SOS/VOD risk factors. Finally these new EBMT criteria for severity grading of SOS/VOD may be used for suspected SOS/VOD, before patients fulfill the diagnostic criteria, especially before day 21 . It may allow early therapeutic intervention in patients with severe or very severe suspected SOS/VOD that do not fulfill yet SOS/VOD diagnostic criteria.

\section{CONCLUSION}

By defining these new EBMT diagnostic and severity criteria for SOS/VOD, we aimed at overcoming the lack of specificity and sensitivity of the current criteria. We acknowledge that our proposal must be ideally prospectively validated in clinical studies. Furthermore, these criteria may not be definitive, as lack of validated biomarkers and of validation/expertise in new imaging modalities prevented us from incorporating them into the new classification. We believe that the new EBMT severity-grading criteria could be a valuable tool to accurately assess the severity of the condition at diagnosis, rather than only retrospectively. Altogether, our proposed diagnostic and severity-grading criteria, when validated in prospective studies, will allow an earlier identification and quantification of SOS/VOD, aiding in the selection of patients requiring immediate therapeutic intervention.

\section{CONFLICT OF INTEREST}

All authors received honoraria and/or research support from JAZZ Pharmaceuticals whose product is discussed in this manuscript. JAZZ pharmaceuticals provided an unrestricted educational grant for support for the current study, but did not participate to the discussions, conduct of the work, data/results analyses or manuscript writing or reviewing. All authors designed the manuscript, analyzed the literature, wrote and commented on the manuscript. All authors approved submission of the manuscript for publication purposes.

\section{ACKNOWLEDGEMENTS}

MM thanks Prof JV Melo (University of Adelaide, Australia) for critical reading of the manuscript. FM was supported by educational grants from the 'Association for Training, Education and Research in Hematology, Immunology and Transplantation' (ATERHIT, Nantes, France). 


\section{REFERENCES}

1 Mohty M, Malard F, Abecassis M, Aerts E, Alaskar AS, Aljurf M et al. Sinusoidal obstruction syndrome/veno-occlusive disease: current situation and perspectives-a position statement from the European Society for Blood and Marrow Transplantation (EBMT). Bone Marrow Transplant 2015; 50: 781-789.

2 Carreras E, Diaz-Ricart M. The role of the endothelium in the short-term complications of hematopoietic SCT. Bone Marrow Transplant 2011; 46: 1495-1502.

3 McDonald GB, Sharma P, Matthews DE, Shulman HM, Thomas ED. Venocclusive disease of the liver after bone marrow transplantation: diagnosis, incidence, and predisposing factors. Hepatology 1984; 4: 116-122.

4 Jones RJ, Lee KS, Beschorner WE, Vogel VG, Grochow LB, Braine HG et al. Venoocclusive disease of the liver following bone marrow transplantation. Transplantation 1987; 44: 778-783.

5 Coppell JA, Richardson PG, Soiffer R, Martin PL, Kernan NA, Chen A et al. Hepatic veno-occlusive disease following stem cell transplantation: incidence, clinical course, and outcome. Biol Blood Marrow Transplant 2010; 16: 157-168.

6 Lee JL, Gooley T, Bensinger W, Schiffman K, McDonald GB. Veno-occlusive disease of the liver after busulfan, melphalan, and thiotepa conditioning therapy: incidence, risk factors, and outcome. Biol Blood Marrow Transplant 1999; 5: 306-315.

7 Carreras E, Rosinol L, Terol MJ, Alegre A, de Arriba F, Garcia-Larana J et al. Veno-occlusive disease of the liver after high-dose cytoreductive therapy with busulfan and melphalan for autologous blood stem cell transplantation in multiple myeloma patients. Biol Blood Marrow Transplant 2007; 13: 1448-1454.

8 Carreras E, Bertz H, Arcese W, Vernant JP, Tomas JF, Hagglund H et al. Incidence and outcome of hepatic veno-occlusive disease after blood or marrow transplantation: a prospective cohort study of the European Group for Blood and Marrow Transplantation. European Group for Blood and Marrow Transplantation Chronic Leukemia Working Party. Blood 1998; 92: 3599-3604.

9 Carreras E, Diaz-Beya M, Rosinol L, Martinez C, Fernandez-Aviles F, Rovira M. The incidence of veno-occlusive disease following allogeneic hematopoietic stem cell transplantation has diminished and the outcome improved over the last decade. Biol Blood Marrow Transplant 2011; 17: 1713-1720.

10 Yakushijin K, Atsuta Y, Doki N, Yokota A, Kanamori H, Miyamoto T et al. Sinusoidal obstruction syndrome after allogeneic hematopoietic stem cell transplantation: Incidence, risk factors and outcomes. Bone Marrow Transplant 2015; 51: 403-409.

11 Richardson PG, Riches ML, Kernan NA, Brochstein JA, Mineishi S, Termuhlen AM et al. Phase 3 trial of defibrotide for the treatment of severe veno-occlusive disease and multi-organ failure. Blood 2016; 127: 1656-1665.

12 Richardson PG, Elias AD, Krishnan A, Wheeler C, Nath R, Hoppensteadt D et al. Treatment of severe veno-occlusive disease with defibrotide: compassionate use results in response without significant toxicity in a high-risk population. Blood 1998; 92: 737-744.

13 Richardson PG, Murakami C, Jin Z, Warren D, Momtaz P, Hoppensteadt D et al. Multi-institutional use of defibrotide in 88 patients after stem cell transplantation with severe veno-occlusive disease and multisystem organ failure: response without significant toxicity in a high-risk population and factors predictive of outcome. Blood 2002; 100: 4337-4343.

14 Richardson PG, Soiffer RJ, Antin JH, Uno H, Jin Z, Kurtzberg J et al. Defibrotide for the treatment of severe hepatic veno-occlusive disease and multiorgan failure after stem cell transplantation: a multicenter, randomized, dose-finding trial. Biol Blood Marrow Transplant 2010; 16: 1005-1017.

15 Corbacioglu S, Cesaro S, Faraci M, Valteau-Couanet D, Gruhn B, Rovelli A et al. Defibrotide for prophylaxis of hepatic veno-occlusive disease in paediatric haemopoietic stem-cell transplantation: an open-label, phase 3, randomised controlled trial. Lancet 2012; 379: 1301-1309.

16 Shulman HM, Hinterberger W. Hepatic veno-occlusive disease--liver toxicity syndrome after bone marrow transplantation. Bone Marrow Transplant 1992; 10: 197-214.

17 McDonald GB, Hinds MS, Fisher LD, Schoch HG, Wolford JL, Banaji M et al. Veno-occlusive disease of the liver and multiorgan failure after bone marrow transplantation: a cohort study of 355 patients. Ann Intern Med 1993; 118: 255-267.

18 Goldberg SL, Shubert J, Rao AK, Redei I, Klumpp TR, Mangan KF. Treatment of hepatic veno-occlusive disease with low-dose tissue plasminogen activator: impact on coagulation profile. Bone Marrow Transplant 1996; 18: 633-636.

19 Hagglund $H$, Ringden O, Ericzon BG, Duraj F, Ljungman P, Lonnqvist B et al. Treatment of hepatic venoocclusive disease with recombinant human tissue plasminogen activator or orthotopic liver transplantation after allogeneic bone marrow transplantation. Transplantation 1996; 62: 1076-1080.

20 Bearman SI, Lee JL, Baron AE, McDonald GB. Treatment of hepatic venocclusive disease with recombinant human tissue plasminogen activator and heparin in 42 marrow transplant patients. Blood 1997; 89: 1501-1506.
21 Ringden O, Remberger M, Lehmann S, Hentschke P, Mattsson J, Klaesson S et al. $\mathrm{N}$-acetylcysteine for hepatic veno-occlusive disease after allogeneic stem cell transplantation. Bone Marrow Transplant 2000; 25: 993-996.

22 Malard F, Chevallier P, Guillaume T, Delaunay J, Rialland F, Harousseau JL et al. Continuous reduced nonrelapse mortality after allogeneic hematopoietic stem cell transplantation: a single-institution's three decade experience. Biol Blood Marrow Transplant 2014; 20: 1217-1223.

23 Dignan FL, Wynn RF, Hadzic N, Karani J, Quaglia A, Pagliuca A et al. BCSH/BSBMT guideline: diagnosis and management of veno-occlusive disease (sinusoidal obstruction syndrome) following haematopoietic stem cell transplantation. $\mathrm{Br} J$ Haematol 2013; 163: 444-457.

24 Carreras E. How I manage sinusoidal obstruction syndrome after haematopoietic cell transplantation. Br J Haematol 2014; 168: 481-491.

25 Soiffer RJ, Dear K, Rabinowe SN, Anderson KC, Freedman AS, Murray C et al. Hepatic dysfunction following T-cell-depleted allogeneic bone marrow transplantation. Transplantation 1991; 52: 1014-1019.

26 Moscardo F, Urbano-Ispizua A, Sanz GF, Brunet S, Caballero D, Vallejo C et al. Positive selection for CD34+ reduces the incidence and severity of veno-occlusive disease of the liver after HLA-identical sibling allogeneic peripheral blood stem cell transplantation. Exp Hematol 2003; 31: 545-550.

27 Kanakry CG, Fuchs EJ, Luznik L. Modern approaches to HLA-haploidentical blood or marrow transplantation. Nat Rev Clin Oncol 2016; 13: 10-24.

28 Nagler A, Labopin M, Berger R, Bunjes D, Campos A, Socie G et al. Allogeneic hematopoietic SCT for adults $\mathrm{AML}$ using i.v. $\mathrm{BU}$ in the conditioning regimen: outcomes and risk factors for the occurrence of hepatic sinusoidal obstructive syndrome. Bone Marrow Transplant 2014; 49: 628-633.

29 Hogan WJ, Maris M, Storer B, Sandmaier BM, Maloney DG, Schoch HG et al. Hepatic injury after nonmyeloablative conditioning followed by allogeneic hematopoietic cell transplantation: a study of 193 patients. Blood 2004; 103: 78-84.

30 Almog S, Kurnik D, Shimoni A, Loebstein R, Hassoun E, Gopher A et al. Linearity and stability of intravenous busulfan pharmacokinetics and the role of glutathione in busulfan elimination. Biol Blood Marrow Transplant 2011; 17: 117-123.

31 Tsirigotis PD, Resnick IB, Avni B, Grisariu S, Stepensky P, Or R et al. Incidence and risk factors for moderate-to-severe veno-occlusive disease of the liver after allogeneic stem cell transplantation using a reduced intensity conditioning regimen. Bone Marrow Transplant 2014; 49: 1389-1392.

32 Cutler C, Stevenson K, Kim HT, Richardson P, Ho VT, Linden E et al. Sirolimus is associated with veno-occlusive disease of the liver after myeloablative allogeneic stem cell transplantation. Blood 2008; 112: 4425-4431.

33 Carmona A, Diaz-Ricart $M$, Palomo $M$, Molina $P$, Pino $M$, Rovira $M$ et al Distinct deleterious effects of cyclosporine and tacrolimus and combined tacrolimus-sirolimus on endothelial cells: protective effect of defibrotide. Biol Blood Marrow Transplant 2013; 19: 1439-1445.

34 Hagglund $\mathrm{H}$, Remberger $\mathrm{M}$, Klaesson $\mathrm{S}$, Lonnqvist $\mathrm{B}$, Ljungman $\mathrm{P}$, Ringden $\mathrm{O}$. Norethisterone treatment, a major risk-factor for veno-occlusive disease in the liver after allogeneic bone marrow transplantation. Blood 1998; 92: 4568-4572.

35 Srivastava A, Poonkuzhali B, Shaji RV, George B, Mathews V, Chandy M et al. Glutathione S-transferase M1 polymorphism: a risk factor for hepatic venoocclusive disease in bone marrow transplantation. Blood 2004; 104: 1574-1577.

36 Kallianpur AR, Hall LD, Yadav M, Byrne DW, Speroff T, Dittus RS et al. The hemochromatosis $\mathrm{C} 282 \mathrm{Y}$ allele: a risk factor for hepatic veno-occlusive disease after hematopoietic stem cell transplantation. Bone Marrow Transplant 2005; 35 : 1155-1164.

37 Efrati E, Zuckerman T, Ben-Ami E, Krivoy N. MTHFR C677T/A1298C genotype: a possible risk factor for liver sinusoidal obstruction syndrome. Bone Marrow Transplant 2014; 49: 726-727.

38 Bearman SI. The syndrome of hepatic veno-occlusive disease after marrow transplantation. Blood 1995; 85: 3005-3020.

39 Wadleigh M, Richardson PG, Zahrieh D, Lee SJ, Cutler C, Ho V et al. Prior gemtuzumab ozogamicin exposure significantly increases the risk of veno-occlusive disease in patients who undergo myeloablative allogeneic stem cell transplantation. Blood 2003; 102: 1578-1582.

40 Kantarjian $\mathrm{H}$, Thomas D, Jorgensen J, Kebriaei $\mathrm{P}$, Jabbour E, Rytting $\mathrm{M}$ et al. Results of inotuzumab ozogamicin, a CD22 monoclonal antibody, in refractory and relapsed acute lymphocytic leukemia. Cancer 2013; 119: 2728-2736.

41 Morado M, Ojeda E, Garcia-Bustos J, Aguado MJ, Arrieta R, Quevedo E et al. BMT: serum ferritin as risk factor for veno-occlusive disease of the liver. Prospective Cohort Study. Hematology 2000; 4: 505-512.

42 Maradei SC, Maiolino A, de Azevedo AM, Colares M, Bouzas LF, Nucci M. Serum ferritin as risk factor for sinusoidal obstruction syndrome of the liver in patients undergoing hematopoietic stem cell transplantation. Blood 2009; 114: 1270-1275.

43 Salat C, Holler E, Kolb HJ, Reinhardt B, Pihusch R, Wilmanns W et al. Plasminogen activator inhibitor-1 confirms the diagnosis of hepatic veno-occlusive disease in 
patients with hyperbilirubinemia after bone marrow transplantation. Blood 1997; 89: 2184-2188.

44 Park YD, Yasui M, Yoshimoto T, Chayama K, Shimono T, Okamura T et al. Changes in hemostatic parameters in hepatic veno-occlusive disease following bone marrow transplantation. Bone Marrow Transplant 1997; 19: 915-920.

45 Kaleelrahman M, Eaton JD, Leeming D, Bowyer K, Taberner D, Chang J et al. Role of plasminogen activator inhibitor-1 (PAl-1) levels in the diagnosis of BMT-associated hepatic veno-occlusive disease and monitoring of subsequent therapy with defibrotide (DF). Hematology 2003; 8: 91-95.

46 Faioni EM, Krachmalnicoff A, Bearman SI, Federici AB, Decarli A, Gianni AM et al. Naturally occurring anticoagulants and bone marrow transplantation: plasma protein $C$ predicts the development of venocclusive disease of the liver. Blood 1993; 81: 3458-3462.

47 Lee JH, Lee KH, Kim S, Lee JS, Kim WK, Park CJ et al. Relevance of proteins C and S, antithrombin III, von Willebrand factor, and factor VIII for the development of hepatic veno-occlusive disease in patients undergoing allogeneic bone marrow transplantation: a prospective study. Bone Marrow Transplant 1998; 22: 883-888.

48 Scrobohaci ML, Drouet L, Monem-Mansi A, Devergie A, Baudin B, D'Agay MF et al. Liver veno-occlusive disease after bone marrow transplantation changes in coagulation parameters and endothelial markers. Thromb Res 1991; 63: 509-519.

49 Tanikawa S, Mori S, Ohhashi K, Akiyama H, Sasaki T, Kaku H et al. Predictive markers for hepatic veno-occlusive disease after hematopoietic stem cell transplantation in adults: a prospective single center study. Bone Marrow Transplant 2000; 26: 881-886.

50 Collins PW, Gutteridge CN, O'Driscoll A, Blair S, Jones L, Aitchison R et al. von Willebrand factor as a marker of endothelial cell activation following BMT. Bone Marrow Transplant 1992; 10: 499-506.

51 Cutler C, Kim HT, Ayanian S, Bradwin G, Revta C, Aldridge J et al. Prediction of veno-occlusive disease using biomarkers of endothelial injury. Biol Blood Marrow Transplant 2010; 16: 1180-1185.

52 Akil A, Zhang Q, Mumaw CL, Raiker N, Yu J, Velez de Mendizabal N et al. Biomarkers for diagnosis and prognosis of sinusoidal obstruction syndrome after hematopoietic cell transplantation. Biol Blood Marrow Transplant 2015; 21: 1739-1745.

53 Mahgerefteh SY, Sosna J, Bogot N, Shapira MY, Pappo O, Bloom Al. Radiologic imaging and intervention for gastrointestinal and hepatic complications of hematopoietic stem cell transplantation. Radiology 2011; 258: 660-671.

54 Lassau N, Leclere J, Auperin A, Bourhis JH, Hartmann O, Valteau-Couanet D et al. Hepatic veno-occlusive disease after myeloablative treatment and bone marrow transplantation: value of gray-scale and Doppler US in 100 patients. Radiology 1997; 204: 545-552.

55 Brown BP, Abu-Yousef M, Farner R, LaBrecque D, Gingrich R. Doppler sonography: a noninvasive method for evaluation of hepatic venocclusive disease. AJR Am J Roentgenol 1990; 154: 721-724.

56 Carreras E, Granena A, Navasa M, Bruguera M, Marco V, Sierra J et al. Transjugular liver biopsy in BMT. Bone Marrow Transplant 1993; 11: 21-26.

57 Shulman HM, Gooley T, Dudley MD, Kofler T, Feldman R, Dwyer D et al. Utility of transvenous liver biopsies and wedged hepatic venous pressure measurements in sixty marrow transplant recipients. Transplantation 1995; 59: 1015-1022.

58 Tasu JP, Rocher L, Peletier G, Kuoch V, Kulh E, Miquel A et al. Hepatic venous pressure gradients measured by duplex ultrasound. Clin Radiol 2002; 57: 746-752.

59 Dignan FL, Scarisbrick JJ, Cornish J, Clark A, Amrolia P, Jackson G et al. Organ-specific management and supportive care in chronic graft-versus-host disease. Br J Haematol 2012; 158: 62-78.

60 Erturk SM, Mortele KJ, Binkert CA, Glickman JN, Oliva MR, Ros PR et al. CT features of hepatic venoocclusive disease and hepatic graft-versus-host disease in patients after hematopoietic stem cell transplantation. AJR Am J Roentgenol 2006; 186: 1497-1501.

61 Zhou H, Wang YX, Lou HY, Xu XJ, Zhang MM. Hepatic sinusoidal obstruction syndrome caused by herbal medicine: CT and MRI features. Korean J Radiol 2014; 15: $218-225$.
62 van den Bosch MA, van Hoe L. MR imaging findings in two patients with hepatic veno-occlusive disease following bone marrow transplantation. Eur Radiol 2000; 10: $1290-1293$.

63 Mortele KJ, Van Vlierberghe H, Wiesner W, Ros PR. Hepatic veno-occlusive disease: MRI findings. Abdom Imaging 2002; 27: 523-526.

64 Dumont C, Lambert M, Van Beers BE. MR imaging findings in a patient with hepatic veno-occlusive disease. Acta Gastroenterol Belg 2004; 67: 236-238.

65 Shin NY, Kim MJ, Lim JS, Park MS, Chung YE, Choi JY et al. Accuracy of gadoxetic acid-enhanced magnetic resonance imaging for the diagnosis of sinusoidal obstruction syndrome in patients with chemotherapy-treated colorectal liver metastases. Eur Radiol 2012; 22: 864-871.

66 Ward J, Guthrie JA, Sheridan MB, Boyes S, Smith JT, Wilson D et al. Sinusoidal obstructive syndrome diagnosed with superparamagnetic iron oxide-enhanced magnetic resonance imaging in patients with chemotherapy-treated colorectal liver metastases. J Clin Oncol 2008; 26: 4304-4310.

67 Carreras E, Granena A, Navasa M, Bruguera M, Marco V, Sierra J et al. On the reliability of clinical criteria for the diagnosis of hepatic veno-occlusive disease. Ann Hematol 1993; 66: 77-80.

68 Rio B, Andreu G, Nicod A, Arrago JP, Dutrillaux F, Samama M et al. Thrombocytopenia in venocclusive disease after bone marrow transplantation or chemotherapy. Blood 1986; 67: 1773-1776.

69 Richardson PG, Smith AR, Triplett BM, Kernan NA, Grupp SA, Arai S et al. Results of the large prospective study on the use of defibrotide (DF) in the treatment of hepatic veno-occlusive disease (VOD) in hematopoietic stem cell transplant (HSCT). Early intervention improves outcome - updated results of a treatment IND (T-IND). ASH Annual Meeting Abstracts 2013; 122: 700-700.

70 Bearman SI, Anderson GL, Mori M, Hinds MS, Shulman HM, McDonald GB. Venoocclusive disease of the liver: development of a model for predicting fatal outcome after marrow transplantation. J Clin Oncol 1993; 11: 1729-1736.

71 Chao N. How I treat sinusoidal obstruction syndrome. Blood 2014; 123: 4023-4026.

72 Gooley TA, Rajvanshi P, Schoch HG, McDonald GB. Serum bilirubin levels and mortality after myeloablative allogeneic hematopoietic cell transplantation. Hepatology 2005; 41: 345-352.

73 Moscardo F, Sanz GF, de La Rubia J, Jimenez C, Saavedra S, Regadera A et al. Marked reduction in the incidence of hepatic veno-occlusive disease after allogeneic hematopoietic stem cell transplantation with $\mathrm{CD} 34(+)$ positive selection. Bone Marrow Transplant 2001; 27: 983-988.

74 Morris JD, Harris RE, Hashmi R, Sambrano JE, Gruppo RA, Becker AT et al. Antithrombin-III for the treatment of chemotherapy-induced organ dysfunction following bone marrow transplantation. Bone Marrow Transplant 1997; 20: 871-878.

75 Gruss E, Bernis C, Tomas JF, Garcia-Canton C, Figuera A, Motellon JL et al. Acute renal failure in patients following bone marrow transplantation: prevalence, risk factors and outcome. Am J Nephrol 1995; 15: 473-479.

76 Kist-van Holthe JE, Goedvolk CA, Brand R, van Weel MH, Bredius RG, van Oostayen JA et al. Prospective study of renal insufficiency after bone marrow transplantation. Pediatr Nephrol 2002; 17: 1032-1037.

77 American College of Chest Physicians/Society of Critical Care Medicine Consensus Conference: definitions for sepsis and organ failure and guidelines for the use of innovative therapies in sepsis. Crit Care Med 1992; 20: 864-874.

cC) $($ (i) $\Theta$ This work is licensed under a Creative Commons Attributioncc) NonCommercial-NoDerivs 4.0 International License. The images or other third party material in this article are included in the article's Creative Commons license, unless indicated otherwise in the credit line; if the material is not included under the Creative Commons license, users will need to obtain permission from the license holder to reproduce the material. To view a copy of this license, visit http:// creativecommons.org/licenses/by-nc-nd/4.0/ 